\title{
Determination of Some Population Dynamic Parameters of Acanthobrama thisbeae Freyhof \& Özuluğ, 2014 for Azaplı Lake (Gölbaşı, Adıyaman)
}

\author{
Nuriye Ahsen KILIÇ${ }^{1}$, Sevil SUNGUR2², Erdoğan ÇiçEK¹ \\ ${ }^{1}$ Department of Biology, Faculty of Art and Sciences, Nevşehir Hacı Bektaş Veli University, 50300, Nevşehir, Turkey. \\ ${ }^{2}$ Health Services Vocational School, Nevşehir Hacı Bektaş Veli University, 50300, Nevşehir, Turkey.
}

\begin{abstract}
Received: 07.11 .2018
Accepted: 05.12.2018

Published online: 10.12 .2018

Issue published: 28.12 .2018

Abstract: The aim of this study was to determine population parameters of Acanthobrama thisbeae in Azapli Lake, Ceyhan River basin. A total of 576 specimens were analyzed that were collected in August 2014, September 2014, and May 2015. Age of the specimens ranged from I to V age groups. Dominant age group was found I (62.85\% ) followed by III and II age groups. Total length varied from $8.6-21.5 \mathrm{~cm}$ with the mean of $12.55 \pm 2.98 \mathrm{~cm}$ and total weight ranged from 5.61 to 107.72 with the mean of $23.43 \pm 19.39$ g. Length-weight relationship were estimated $W=0.0053 L^{3.2364}$. Estimated population parameters were calculated as $L_{\infty}: 26.74 \mathrm{~cm}, k: 0.241 . t_{0}:-1.13 . \Phi^{\prime}: 2.24$ and $K: 0.91$ for the population. Mortality and exploitation rates estimated as $Z: 0.76, M$ : $0.55, F: 0.21$ and E: 0.27 , respectively. According to these values, it is expected that there are no over-fishing pressure on the population.
\end{abstract}

Keywords: Acanthobrama thisbeae, Azaplı Lake, Aksu River, length-weight relation, population dynamics, Ceyhan River basin.

\section{Azaplı Gölü (Gölbaşı, Adıyaman)'ndeki Acanthobrama thisbeae Freyhof \& Özuluğ, 2014'nin Bazı Popülasyon Dinamiği Parametrelerinin Belirlenmesi}

Öz: Bu çalışma, Acanthobrama thisbeaénin Azaplı Gölü popülasyonuna ait bazı popülasyon dinamiği parametrelerinin belirlenmesi amacıyla gerçekleştirilmiştir. Çalışma Ağustos 2014, Eylül 2014 ve Mayıs 2015 tarihlerinde avlanan 576 bireyde yapılmıştır. Bireylerin yaşları I-V arasında belirlenmiştir. Örneklenen I. yaş grubu en baskın (\% 62.85) olup, bunu sırasıyla III. ve II. yaş grupları izlemiştir. İncelenen bireylerin boy değerleri 8.6-21.5 cm ve ağırlık değerleri ise 5.61-107.72 g arasında olup ortalama boy ve ağırlık değerleri sırasıyla $12.55 \pm 2.98 \mathrm{~cm}$ ve $23.43 \pm 19.39 \mathrm{~g}$ olarak hesaplanmıştır. Boy-ağırlık ilişkisi ise $W=0.0053 L^{3.2364}$ olarak belirlenmiştir. Popülasyon parametreleri $L_{\infty}: 26.74 \mathrm{~cm}, k: 0.241 . t_{0}:-1.13$. $\Phi^{\prime}: 2.24$ ve $K: 0.91$ olarak hesaplanmıştır. Ölüm oranları ve stoktan yararlanma düzeyi ise $Z: 0.76 . M: 0.55, F: 0.21$ ve E: 0.27 olarak tahmin edilmiştir. Bu bulgulara göre popülasyon üzerinde aşırı avcılık baskısının bulunmadığı söylenebilir.

Anahtar kelimeler: Acanthobrama thisbeae, Azaplı Gölü, Aksu Nehri, boy-ağırlık ilişkisi, popülasyon dinamiği, Ceyhan Havzası

\section{Giriş}

Balıklarda popülasyon parametreleri türe özgü olduğu kadar aynı türün farklı bölgelerdeki stokları arasında da değişiklik göstermektedir. Bu parametreler aynı habitatta yıllara göre de değişimler göstermektedir. Değişiklikler yaşam alanlarının biyotik ve abiyotik faktörlerinin etkisi altındadır (Avşar, 2005).

Stoklardan uygun ölçüde ve sürdürülebilir şekilde yararlanmak ve alınabilecek önlemlerin belirlenmesi açısından popülasyonların yaş, boy, ağırlık dağılımları ile kondisyon ve boy-ağırlık ilişkileri gibi bazı parametrelerinin bilinmesi gerekmektedir.

Balıklarda büyüme, zamana bağlı olarak ortaya çıkan vücut kütlesinde artışı ifade etmektedir. Büyüme anabolizmanın katabolizmadan yüksek olması nedeniyle diğer bazı omurgalılarda olduğu gibi belli bir süre sonra durmayıp tüm yaşamları boyunca sürer. Büyüme farklı türlerin genotipik yapısına bağlı olarak değişiklik gösterebildiği gibi aynı türün farklı ekosistemlerdeki stoklarında iklimsel ve fizikokimyasal parametrelere bağlı olarak da değişiklik göstermektedir (Sarıhan, Çiçek, \& Toklu, 2007).

Balık popülasyonlarında doğal etmenler ve balıkçılık faaliyetleri kaynaklı ölüm oranlarının belirlenmesi gerekmektedir. $\mathrm{Bu}$ oranlara bağlı olarak stoktan ne düzeyde yararlanıldığı belirlenebilecektir (Sparre \& Venema, 1998).

Freyhof ve Özuluğ (2014) tarafindan tanımlanan Acanthobrama thisbeae'nin Ceyhan ve Asi havzalarında dağılım gösterdiği bildirilmektedir (Freyhof \& Özuluğ, 2014). Bu türün daha önce Ceyhan ve Asi havzalarından kayıt verilen A. marmid olduğu belirtilmektedir (Alp, Bülbül, \& Büyükçapar, 2004; Alp \& Büyükçapar, 2006; Kara, Alp, \& Şimşekli, 2010; Erk'akan \& Özdemir, 2011; Dağl1, 2015; Erdoğrul \& Bülbül, 2006; Erdoğrul \& Ateş, 2006). Küçük boylu olup ekonomik değeri düşüktür; ancak bölgesel olarak avlanıp besin olarak tüketilmektedir (Erdoğrul \& Bülbül, 2006; Alp \& Büyükçapar, 2006). Besin zincirinin alt halkalarında yer alan, süzücü olarak planktonik organizmalarla ve diğer omurgasızlarla beslenmeleri nedeniyle, A. thisbeae'nin beslenme özelliği bakımından ekosistemde besin piramidinin alt basamaklarından üst basamaklarına enerji ve maddenin akışı bakımından önemli bir işlevi vardır (Kılıç, 2006).

Bu çalışma ile Azaplı Gölü A. thisbeae türüne ait bazı popülasyon dinamiği parametrelerinin belirlenmesi amaçlanmıştır. Acanthobrama thisbeae'nın biyoekolojik özelliklerinin belirlenmesine yönelik olarak henüz hiçbir çalışma gerçekleştirilmemiştir. Bu çalışma, söz konusu tür üzerinde yapılmış ilk çalışma niteliğini taşımaktadır. 


\section{Materyal ve Metot}

Çalışma, Ceyhan Havzasında yer alan Azaplı Gölü'nde $\left(37^{\circ} 45^{\prime} 0^{\prime \prime K} \mathrm{~K}-37^{\circ} 32^{\prime} 59^{\prime \prime} \mathrm{D}\right) \quad$ yürütülmüştür. Gölbaş1 Depresyonu, Doğu Anadolu Fay Zonu üzerinde yer alan önemli depresyonlardan birisi olup yerkabuğunun en önemli tektonik arızalarından Anadolu'daki devamı üzerindedir. Depresyon tabanının çukur yerlerinde Gölbaşı, Azaplı ve İnekli gölleri yer almakta olup 2008 yılında Gölbaşı Gölleri Tabiat Parkı olarak ilan edilmiştir (Yönlü, Altunel, Karabacak, \& Akyüz, 2013). Bu göller arasında en derin göl, Azaplı Gölüdür. Gölbaşı Gölünün fazla gelen suları Azaplı Gölüne, bu gölün fazla suları İnekli Gölüne, bu üç gölün fazla suları ise Aksu Çayına boşalmaktadır (Biricik, 1994). Sulak alanın kıyısında ince bir şerit halinde bataklık ve sazlıklar, gölleri kuşatmakta olup Afrika ile Avrupa arasındaki göçmen kuşların kullandığı göç yolu üzerinde yer almaktadır (Korkmaz, Karabulut, \& Gürbüz, 2008).

Örnekler $2.5 \mathrm{~m}$ uzunluk ve $6 \mathrm{~m}$ derinliğe sahip farklı göz açıklıkları olan 11 adet toplam $27.5 \mathrm{~m}$ uzunluktaki pelajik ağlar kullanılarak Ağustos 2014, Eylül 2014 ve Mayıs 2015 aylarında birer defa olmak üzere üç defa saha çalışması ile toplanmıştır (Anonim, 2006). Ağlar gün batımından önce atılmış gün doğumunda toplanmıştır. Örnekler \% 4'lük formaldehit çözeltisi içerisinde laboratuara getirilerek muhafaza edilmiştir.

Laboratuvarda muhafaza edilen örneklere ait standart boy, çatal boy ve total boy ölçümleri $1 \mathrm{~mm}$ hassasiyetle, total ağırlık ise $0.01 \mathrm{~g}$ hassasiyetli elektronik hassas terazi kullanılarak belirlenmiştir. Yaş tayini amacıyla, ölçüm değerleri alınmış olan bireylerin vücutlarının yan kısımlarından alınan pul örnekleri ışık mikroskobu altında incelenerek büyüme halkaları iki farklı okuyucu tarafından sayılmıştır (Sarıhan et al., 2007).

Boy-ağırlık ilişki sabitlerinin belirlenmesi amacıyla Regresyon Yöntemi kullanılmıştır: $W=a L^{b}$, bu eşitlikte; $W$ : total ağırlık (g), $a$ ve $b$ : regresyon sabitleri ve $L$ : total boyu $(\mathrm{cm})$ göstermektedir (Sparre \& Venema, 1998).

von Bertalanffy boyca ve ağırlıkça büyüme eşitliği belirlenmiştir: $L_{t}=L_{*}\left[1-e^{-k(t-t o)}\right]$ ve $W_{t}=W_{*}\left[1-e^{-k(t-t o)}\right]$, bu eşitlikte; $L t$ : $\mathrm{t}^{\prime}$ inci yaştaki balığın boyu $(\mathrm{cm}), L_{\infty}$ : sonuşmaz uzunluğu $(\mathrm{cm}), W_{\infty}$ : sonuşmaz ağırlık $(\mathrm{g}), k$ : Brody'nin büyüme katsayısı $\left(\mathrm{y}^{1}{ }^{-1}\right)$ ve $t_{0}$ : balığın yumurtadan çıktığ andaki kuramsal yaşını (yıl) ifade etmektedir (Sparre \& Venema, 1998).

Fulton'un Kondisyon Faktörü $(K)$ tahmin edilmiştir: $K=100 \frac{W}{L^{b}}$, bu eşitlikte; $W$ : total ağırlık (g), L: total boy (cm) ve $b$ : regresyon sabitini göstermektedir (Sparre \& Venema, 1998).

Büyüme performans indeksi $\left(\Phi^{\prime}\right)$ belirlenmiştir (Pauly \& Munro, 1984): $\Phi^{\prime}=\log k+2 \log L_{\infty}$, bu eşitlikte; $\Phi$ : büyüme performans indeksini, $L_{\infty}$ : sonuşmaz uzunluğu (cm), $\quad k$ : Brody'nin büyüme katsayısını (yıl-1) göstermektedir.

Azaplı Gölü A. thisbeae popülasyonu için doğal ölümlerin üssi katsayısının $(Z)$ hesaplanmasında Beverton ve Holt (1957) tarafindan önerilen ortalama boy değeri kullanılmıştır (Beverton \& Holt, 1957): $Z=$ $k \frac{\left(L_{\infty}-\bar{L}\right)}{\left(\bar{L}-L^{\prime}\right)}$, bu eşitlikte; Z: toplam ölümlerin üssi katsayısı, $L_{\infty}$ : sonuşmaz uzunluğu $(\mathrm{cm}), \bar{L}$ : incelenen bireylerin ortalama boyu $(\mathrm{cm}), \bar{L}$ : incelenen bireylerden en küçük boylu balıkların bulunduğu sinif aralığı $(\mathrm{cm})$ ve $k$ : Brody'nin büyüme katsayısını $\left(\mathrm{yll}^{-1}\right)$ göstermektedir.

Balıklarda doğal nedenlerle meydana gelen ölüm oranlarının üssi katsayısının $(M)$ belirlenmesinde ise von Bertalanffy büyüme sabitleri ile balıkların yaşadıkları su ortamının yıllık ortalama su sicaklığına dayalı olarak Pauly tarafından geliştirilmiş olan deneysel formülden yararlanılmıştır (Pauly, 1980).

$\log 10 \mathrm{M}=-0.0152-0.279 \log 10 \mathrm{~L}_{\infty}+0.6543 \log 10 \mathrm{k}+0.463 \log 10 \mathrm{~T}$

$\mathrm{Bu}$ eşitlikte; $M$ : doğal nedenlerle olan ölüm oranlarının üssi katsayısı, $L_{\infty}$ : sonuşmaz uzunluğu $(\mathrm{cm}), k$ : Brody'nin büyüme katsayısı $\left(\mathrm{y}^{-1} \mathrm{l}^{-1}\right)$ ve $T$ : incelenen popülasyonun yaşadığ 1 yıllık ortalama su sıcaklığını $\left({ }^{\circ} \mathrm{C}\right)$ göstermektedir (Pauly, 1980).

Yukarıdaki eşitlikte ihtiyaç duyulan yıllık ortalama su sıcaklığı değerine ilişkin Azaplı Gölünde daha önce yapılmış herhangi bir çalışmaya rastlanmamıştır. Karakaya, Şen, Gölbaşı, Özer ve Gölbaşı (2014) tarafından, çalışma alanına yakın bir konumda bulunan Atatürk Barajında derinliğe bağlı yıllık su sıcaklığı ölçümleri gerçekleştirilmiştir. Bu çalışmada elde edilen bulgular dikkate alınarak Pauly'nin eşitliğinde kullanılacak bu değer $16^{\circ} \mathrm{C}$ olarak kabul edilmiştir.

Balıkçılık nedeniyle meydana gelen ölümlerin üssi katsayısının $(F)$ belirlenmesinde ise toplam ölüm oranı ile doğal ölümler arasındaki farktan yararlanılmıştır: $F=Z-M$, bu eşitlikte; F: balıkçılık nedeniyle olan ölümlerin üssi katsayısı, Z: toplam ölümlerin üssi katsayısı ve $M$ : doğal nedenlerle olan ölüm oranlarının üssi katsayısını ifade etmektedir.

Sömürülme oranı $(E)$ stoktan yararlanma düzeyinin hesaplanmasında popülasyon için belirlenmiş olan ölüm oranlarının üssi katsayıları kullanılmıştır: $E=\frac{F}{Z^{\prime}}$ bu eşitlikte; $E$ : sömürülme oranı, $Z$ : toplam ölümlerin üssi katsayısı ve $M$ : doğal nedenlerle olan ölüm oranlarının üssi katsayısını ifade etmektedir (Sparre \& Venema, 1998).

İki okuyucu arasındaki uyumun belirlenmesi amacıyla yüzde uyum ve Varyasyon Katsayısı (\%) hesaplanmıştır.

$V K=\frac{S}{\bar{x}} * 100$, bu eşitlikte; $S:$ Standart sapmayı ve $\bar{x}:$ Ortalamayı ifade etmektedir.

Age Bias Plots yöntemi ile okuyucuların aynı birey için belirlemiş oldukları yaş okuma değerleri grafik üzerine yerleştirilerek okuyucular arasındaki farklılıklar ortaya konmuştur (Campana, Annand, \& McMillan, 1995).

Ölçülen ve eşitlikler yardımıyla hesaplanan boy ve ağırlık değerleri arasında istatistiksel anlamda herhangi bir farkın olup olmadığı Khi Kare $\left(X^{2}\right)$ Testi ile belirlenmiştir.

\section{Sonuçlar ve Tartışma}

\subsection{Yaş, boy ve ağırlık dağılımı}

Avlanan 576 bireye ait yaş, ortalama total boy ve ağırlık değerleri, boy ve ağırlık değerlerinin değişim aralıkları belirlenmiştir. Pullardan yaş okuması iki farklı kişi tarafından yapılmış ve karşılaştırılmıştır. Yaş okumaya ilişkin karşılaştırmalı grafik (Age Bias Plot) çizilmiştir 
(Şekil 1). Buna göre okuyucular arasında II. ve III. yaş gruplarında benzerlik görülürken, IV ve I. Yaş gruplarında ise farklılıklar olduğu tespit edilmiştir (Şekil 2). Okuyucular arasında yapılan karşılaştırma da iki okuyucunun \% 92'den daha fazla oranda aynı yaşı belirledikleri saptanmıştır. Tüm yaş grupları için iki okuyucu arasındaki ortalama değişim katsayısı ise \% 13.2 olarak hesaplanmıştır.

Bireylerin yaşının I-V arasında değişim gösterdiği tespit edilmiştir. I. yaş grubunun baskın (\% 62.85), bunu \% 17.19'luk bir oran ile III. ve \% 13.02'lik bir oran ile de II. yaş grubunun izlediği, en düşük oranın ise \% 0.35 ile V. yaş grubuna ait olduğu belirlenmiştir.

Total boy değerlerinin 8.6 ile $21.5 \mathrm{~cm}$ arasında değişim gösterdiği saptanmış olup ortalama $12.55 \pm 2.98$ cm olarak hesaplanmıştır (Tablo 1).

Total ağırlık değerlerinin 5.61 ile $107.72 \mathrm{~g}$ arasında değişim gösterdiği tespit edilmiş olup ortalama ağırlık $23.43 \pm 19.39 \mathrm{~g}$ olarak belirlenmiştir (Tablo 2). En yüksek büyüme oranının II. yaş grubuna kadar olan dönemde gerçekleştiği, takip eden yaş gruplarında ise gerek boyca ve gerekse ağırlıkça büyümenin oransal olarak azalış gösterdiği tespit edilmiştir.

Total boy ve total ağırlık değerleri için frekans dağılımları Şekil $3^{\prime}$ de verilmiştir. Buna göre popülasyonda $10 \mathrm{~cm}$ boy grubunun en baskın boy grubu olduğu görülmekte olup bunu 11 ve $12 \mathrm{~cm}$ boy gruplarının izlediği belirlenmiştir.

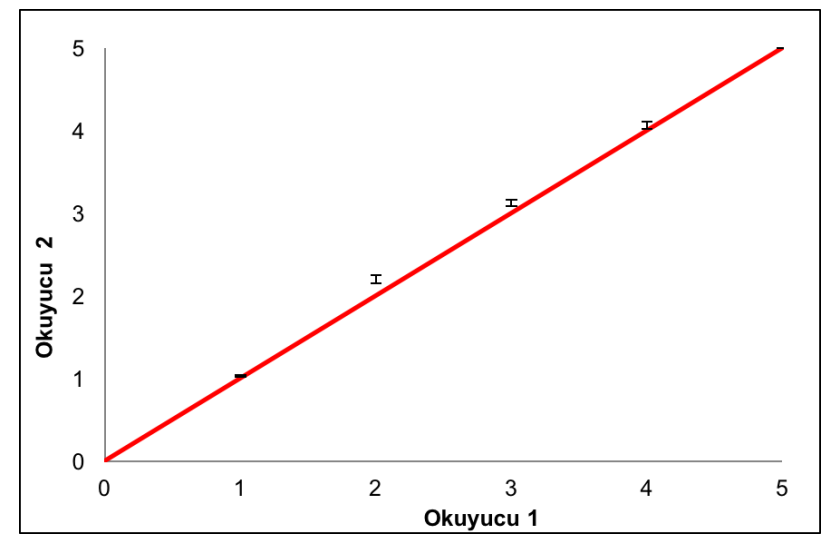

Şekil 1: Pullardan yaş okuması yapan iki okuyucu arasındaki fark grafiği (Age Bias Plot)

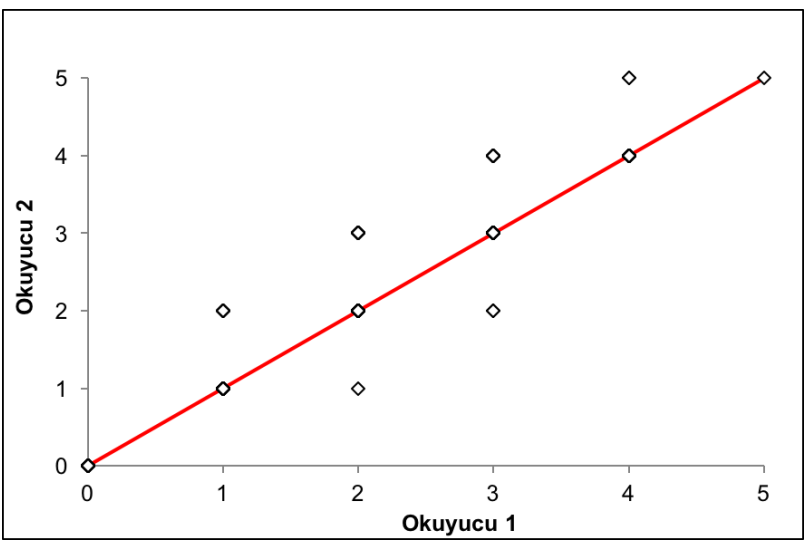

Şekil 2: Pullardan yaş okuması yapan iki okuyucunun her yaş grubu için arasındaki fark

Tablo 1: Azaplı Gölü Acanthobrama thisbeae popülasyonuna ait yaş-boy frekans dağılımı, her yaş grubu için ortalama boy değerleri ve büyüme oranı (BO)

\begin{tabular}{|c|c|c|c|c|c|c|c|c|}
\hline \multirow[b]{2}{*}{ Yaş } & \multirow[b]{2}{*}{$\mathbf{N}$} & \multirow[b]{2}{*}{$\% \mathbf{n}$} & \multicolumn{3}{|c|}{ Total Boy $(\mathrm{cm})$} & \multicolumn{3}{|c|}{ Total Ağırlık (g) } \\
\hline & & & $\begin{array}{c}\text { Değisisim } \\
\text { Aralığı }\end{array}$ & Ortalama Boy & BO $(\%)$ & Değişim Aralığı & $\begin{array}{l}\text { Ortalama } \\
\text { Ağırlık }\end{array}$ & BO $(\%)$ \\
\hline I & 362 & 62.85 & $8.6-12.9$ & $10.47 \pm 0.84$ & & $10.84 \pm 2.83$ & $5.61-20.23$ & \\
\hline II & 75 & 13.02 & $12.3-15.9$ & $14.36 \pm 0.90$ & 37.15 & $30.34 \pm 6.34$ & $15.24-43.47$ & 171.15 \\
\hline III & 99 & 17.19 & $13.8-18.6$ & $16.39 \pm 1.02$ & 14.14 & $46.16 \pm 10.07$ & $28.23-73.03$ & 85.23 \\
\hline IV & 37 & 6.42 & $16.0-20.0$ & $18.38 \pm 0.94$ & 12.14 & $67.49 \pm 12.37$ & $40.78-87.65$ & 44.45 \\
\hline $\mathrm{V}$ & 2 & 0.35 & $19.8-21.5$ & $20.65 \pm 1.20$ & 12.35 & $96.07 \pm 16.48$ & $84.41-107.72$ & \\
\hline$\Sigma$ & 576 & & $8.6-21.5$ & $12.55 \pm 2.98$ & & $23.43 \pm 19.39$ & $5.61-107.72$ & \\
\hline
\end{tabular}

Yaş, boy ve ağırlıkça büyüme değerleri dikkate alındığında, $A$. thisbeae'nin küçük boylu ve nispeten kısa ömürlü bir balık olduğu görülmektedir. Gerek örneklenen birey sayısı gerekse farklı mevsimlerde örnekleme yapılmış olması düşünüldüğünde bu tür için maksimum yaşın $\mathrm{V}$ olduğu belirlenmiştir.

\subsection{Boy-boy ve boy-ağırlık ilişkisi}

Daha önce yapılmış olan popülasyon dinamiği çalışmalarında çatal boy değerlerinin kullanıldığ görülmüştür. Bu nedenle farklı çalışmalarda elde edilen sonuçların karşılaştırılması ve yorumlanmasında kolaylık olması bakımından birliktelik sağlamak amacıyla morfometrik ölçüm değerleri belirlenmiş olan bireyler için total boy-çatal boy ve total boy-standart boy arasındaki ilişkileri $\quad \mathrm{C} B=\left(0.9103^{*} \mathrm{TL}\right)-0.1424$. $\mathrm{SB}=\left(0.8154^{*} \mathrm{TL}\right)-0.2365$ ve $\mathrm{C} B=\left(1.115^{*} \mathrm{SB}\right)-0.3876$ olarak formüle edilmiştir.
Boy-ağırlık ilişkisi $\quad W=0.0053^{*} L^{3.2364}$ olarak belirlenmiştir (Şekil 4). Bu çalışmada elde edilen bireylerden hesaplanan $b$ değerinin \% 95'lik güven aralığ 3.206-3.267 olarak hesaplanmış olup büyümenin pozitif allometrik özellik sergilediği belirlenmiştir $(p<0.05)$. Hesaplanmış olan $a$ değeri dikkate alındığında bireylerin düşük bir kondisyona sahip olduğu ileri sürülebilir.

\section{3. von Bertalanffy büyüme sabitleri ve büyüme karakteristiği}

Popülasyona ait von Bertalanffy büyüme sabitleri $L_{\infty}=26.74 \mathrm{~cm}, k=0.241 \mathrm{yll}^{-1}$ ve $t_{0}=-1.13$ yil olarak tahmin edilmiştir. von Bertalanffy büyüme parametreleri kullanılarak boyca ve ağırlıkça büyüme denkleminden yararlanılarak, her yaş grubu için boy ve ağırlık değerleri hesaplanmıştır. Hesaplanan ve ölçülen değerlere göre ağırlıkça ve boyca büyüme grafikleri (Şekil 5, 6) oluşturulmuş olup aralarında istatistiksel anlamda herhangi bir farklılık olmadığı görülmüştür ( $p>0.05)$. 


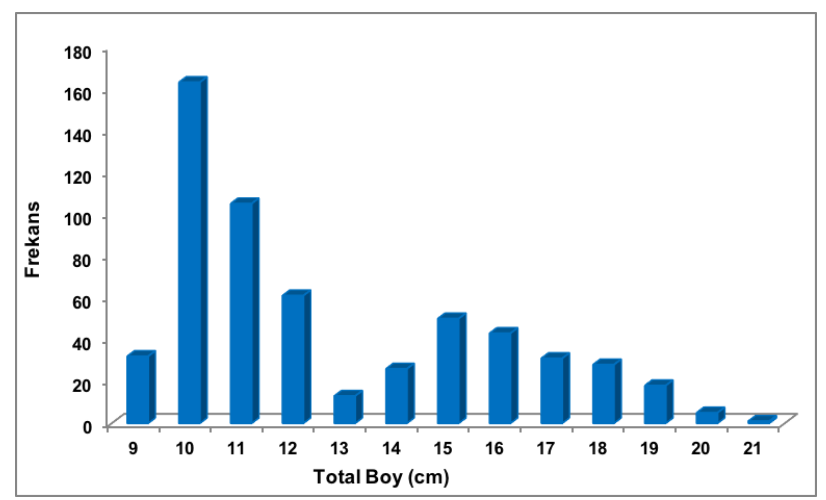

Şekil 3: Azaplı Gölü Acanthobrama thisbeae popülasyonuna ait total boy-frekans dağılımı

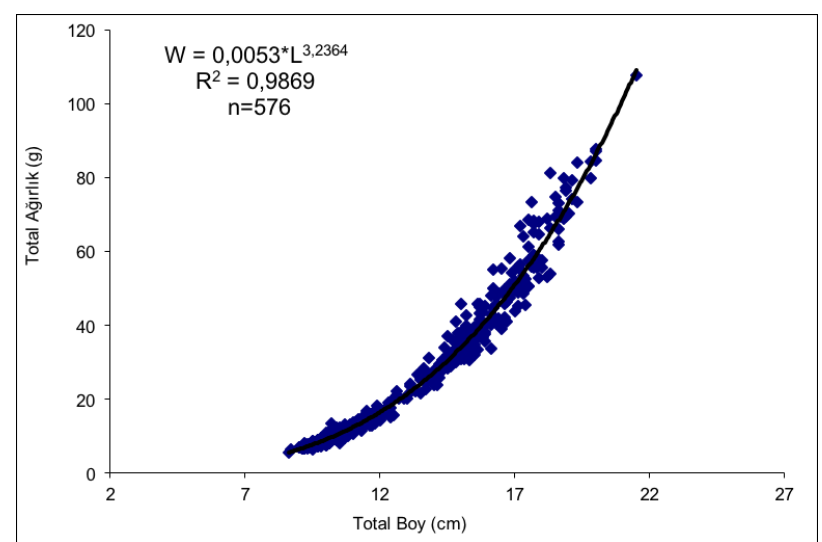

Şekil 4: Azaplı Gölü Acanthobrama thisbeae popülasyonuna ait boy-ağırlık ilişkisi grafiği

Boy-ağırlık ilişki sabitlerinden $a$ değeri, ilgili türün incelenen periyot içindeki kondisyonunu göstermektedir. Farklı dönemler ve popülasyonlar için hesaplanmış olan $a$ değerinin karşılaştırması için bu değerin sabit (izometrik) tutulması gerekmektedir. Büyümenin allometrik olduğu durumlarda ise, balıklarda besililik düzeyinin yorumlanmasında Fulton' un Kondisyon Faktöründen $(K)$ yararlanılmaktadır (Avşar, 2005). Bu değer ortalama $0.91 \pm 0.09$ olarak hesaplanmıştır. Kondisyon Faktörü değerinin türden türe değişiklik gösterebileceği gibi, tür içerisinde de yaş, cinsiyet, mevsimsel koşullar (özellikle de sıcaklık), cinsi olgunluk ve üreme, beslenme şartları ve diğer habitat koşullarına göre değişim gösterdiği bilinmektedir (Avşar, 2005). Büyüme performans indeksi $(\Phi)$ ise 2.24 olarak tahmin edilmiştir.

\section{4. Ölüm oranları ve stoktan yararlanma düzeyi}

$\mathrm{Bu}$ çalışma kapsamında belirlenmiş olan popülasyon dinamiği parametreleri kullanılarak türe ait toplam ölüm oranı (Z) 0.76 olarak hesaplanmıştır. Popülasyon için doğal nedenlerle meydana gelen ölüm oranının $(M=0.55)$ balıkçlık nedeniyle meydana gelen ölüm oranından $(F=0.21)$ yüksek olduğu anlaşılmaktadır. Bu değerlere bağlı olarak hesaplanmış olan sömürülme oranı $(E) 0.27$ olarak bulunmuştur. $E$ değerinin $0.5^{\prime}$ in oldukça altında olması tür üzerinde avcılık baskısının söz konusu olmadığını göstermektedir. Sürdürülebilir bir avcılık için stoktan optimum düzeyde yararlanılması ve aşırı avcılık baskısının yaratılmaması gerekmektedir (Sparre \& Venema, 1998). Acanthobrama thisbeae bölgesel olarak avlansa ve tüketilse de, ticari öneme sahip olmaması nedeniyle hedef tür değildir. Nitekim Türkiye'de, bazı tatlı su balıklarının avlanması için yapılan avcılık sırasında yakalanma haricinde, özel olarak bu türün avcılığına yönelik bir avcılık faaliyeti söz konusu değildir.

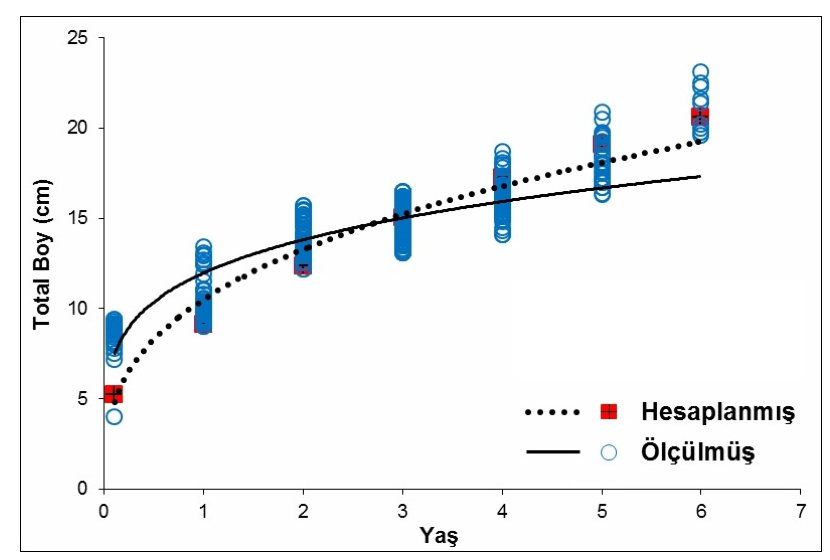

Şekil 5: Azaplı Gölü Acanthobrama thisbeae popülasyonu için hesaplanan ve ölçülen boy değerlerine ait büyüme grafiği

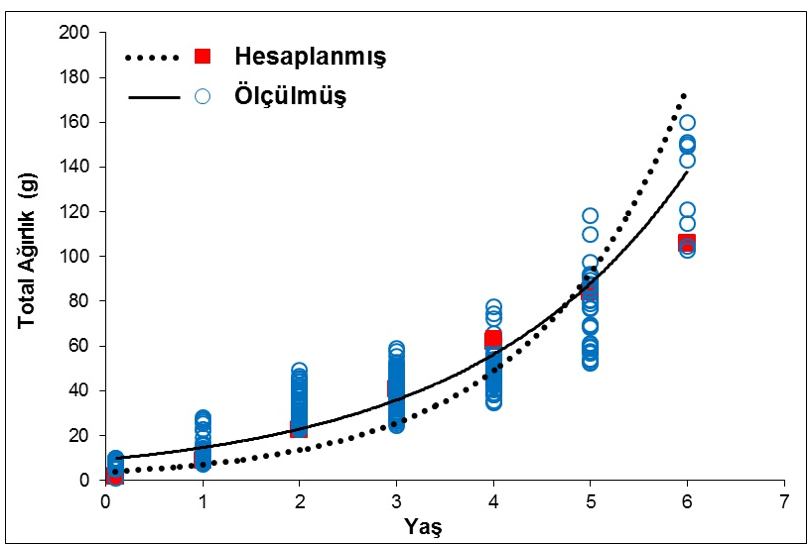

Şekil 6: Azaplı Gölü Acanthobrama thisbeae popülasyonu için hesaplanan ve ölçülen ağırlık değerlerine ait büyüme grafiği

Teşekkür: Birinci yazarın yüksek lisans tezi olan bu çalışmada gerekli laboratuar ve ekipman Nevşehir Hacı Bektaş Veli Üniversitesi Fen Edebiyat Fakültesi Biyoloji Bölümü Hidrobiyoloji Araştırma Laboratuvarı́ndan temin edilmiştir. Dr. Sevil Sungur Birecikligil, arazi ve laboratuvar çalışmaları ile makalenin yazımı aşamalarında katkı sağlamıştır.

\section{Kaynaklar}

Alp, A., \& Büyükçapar, H.M. (2006). Kahramanmaraş'ta su ürünleri sektörünün gelişimi ve balıkçılığa uygun su kaynakları. KSÜ Fen ve Mühendislik Dergisi, 9(1), 104-110.

Alp, A., Bülbül, O., \& Büyükçapar, H.M. (2004). Kahramanmaraş'ta Su Ürünleri Sektörünün Gelişimi ve Balıkçılığa Uygun Su Kaynakları. I. Kahramanmaraş Sempozyumu, 6-8 Mayis 2004, Kahramanmaraş, Türkiye, 3. 1533-1542.

Anonim (2006). TS EN 14757-Su Kalitesi-Değişen Göz Açıklıklı Sık Örgülü Ağlarla Balık Numunesi Alınması. Türk Standartları Enstitüsü, Ankara, 27.

Avşar, D. (2005). Balıkçılık Biyolojisi ve Popülasyon Dinamiği. Nobel Kitapevi, Adana, 332 pp.

Beverton, R.J.H., \& Holt, S.J. (1957). On the Dynamics of Exploited Fish Populations. Great Britain, Ministry of Agriculture, Fisheries and Food, Fishery Investigations Series, 19, 533pp.

Biricik, A.S. (1994). Gölbaşı Depresyonu (Adıyaman). Türk Coğrafya Dergisi, 29, 53-81.

Campana, S.E., Annand, C.M., \& McMillan, J.I. (1995). Graphical and statistical methods for determining the consistency of age determinations. Transactions of the American Fisheries Society, 124, 131138.

Dağlı, M. (2015). Biodiversity and conservation status of fish of Ceyhan River basin in Osmaniye, Turkey. Front. Mar. Sci. Conference Abstract: XV European Congress of Ichthyology. http://dx.doi.org/10.3389/conf.FMARS.2015.03.00181. 
Erdoğrul, Ö., \& Ateş, D.A. (2006). Determination of Cadmium and Copper in Fish Samples From Sır and Menzelet Dam Lake Kahramanmaraş, Turkey. Environmental Monitoring and Assessment, 117, 281-290.

Erdoğrul, Ö., \& Bülbül, O. (2006). Kahramanmaraş Balık Halinde Satılan Acanthobrama marmid (Heckel, 1843) ve Halin Genel Hijyenik Durumunun Mikrobiyolojik Yönden Değerlendirilmesi. KSÜ Fen ve Mühendislik Dergisi, 9(2), 41-45.

Erk'akan, F., \& Özdemir, F. (2011). Revision of the Fish Fauna of the Seyhan and Ceyhan River Basins in Turkey. Research Journal of Biological Sciences, 6, 1-8.

Freyhof, J., \& Özuluğ, M. (2014). Acanthobrama thisbeae, a new species of bream from southern Anatolia, Turkey (Teleostei: Cyprinidae). Ichthyological Exploration of Freshwaters, 25, 1-10.

Kara, C., Alp, A., \& Şimşekli, M. (2010). Distribution of Fish Fauna on the Upper and Middle Basin of Ceyhan River, Turkey. Turkish Journal of Fisheries and Aquatic Sciences, 10, 111-122.

Karakaya, G., Şen, B., Gölbaşı, S., \& Özer Gölbaşı, G. (2014). Atatürk Baraj Gölü'nde Sıcaklık ve Çözünmüş Oksijenin Derinliğe Bağlı Değişimleri. Adryaman Üniversitesi Fen Bilimleri Dergisi, 4(2), 82-90.

Kılıç, N.A. (2016). Acanthobrama thisbeae Freyhof \& Özuluğ, 2014 Azaplı Gölü (Gölbaşi, Adıyaman) Popülasyonu İçin Bazı Popülasyon Dinamiği Parametrelerinin Belirlenmesi. Nevşehir Hacı Bektaş Veli Üniversitesi, Fen Bilimleri Enstitüsü, Yüksek Lisans Tezi.

Korkmaz, H., Karabulut, M., \& Gürbüz, M. (2008). Water Potential of the Gölbaşı Lakes and Their Sustainable Management. J. Int. Environmental Application \& Science, 3(5), 390-398.

Pauly, D. (1980). On the interrelationships between natural mortality, growth parameters, and mean environmental temperature in 175 fish stocks. Conseil International pour l'Exploration de la Mer, 39, 175-192.

Pauly, D., \& Munro, J.L. (1984). Once more on the comparison of growth in fish and invertebrates. Fishbyte, 2(1),1- 21.

Sarıhan, E., Çiçek, E., \& Toklu, B. (2007). Balık Biyolojisine Giriş. Nobel Kitabevi, Adana, 137 pp.

Sparre, P., \& Venema, S.C. (1998). Introduction to tropical fish stock assessment. Part 1. Manual. FAO Fisheries Technical Paper. No. 306. 1 Rev.2. Rome, FAO. 407 pp.

Yönlü, Ö., Altunel, E., Karabacak, V., \& Akyüz, H.S. (2013). Evolution of the Gölbaşı basin and its implications for the long-term off set on the East Anatolian Fault Zone, Turkey. Journal of Geodynamics, 65, 272-281. 